\title{
A Novel Service Oriented Architecture (SOA) TO SECURE SERVICES IN E-CITY
}

\author{
Sajjad Hashemi ${ }^{1}$, Seyyed Yasser Hashemi ${ }^{2}$ and Khalil Monfaredi ${ }^{3}$ \\ ${ }^{1}$ Department of Computer Engineering, Science and Research Branch, Islamic Azad \\ University, West Azarbayjan, Iran \\ ${ }^{2}$ Department of Computer Engineering, miyandoab Branch, Islamic Azad University, \\ miyandoab, Iran \\ ${ }^{3}$ Engineering Faculty, Department of Electrical and Electronic Engineering, Azarbaijan \\ Shahid Madani University, Tabriz, Islamic Republic of Iran
}

\begin{abstract}
Many cities in the world have moved toward being e-city using IT and there are some who have implemented it and or seeking out to make it operational. However, experience shows that implementation of e-city faces Challenges which the effectiveness of e-city, improvement of provided services and security are the most important part of these challenges. Today, for realization of a perfect e-city, to overcome faced challenges Such as security issues is an urgent need. Considering that e-city consists of multiple information systems, it's the most important challenge to create integration between these systems and provide its security which service oriented architecture as a computational model and an approach for data integration could largely overcome these problems. In this paper through studying challenges of information systems in e-city layers and with concentrating on advantages of service oriented architecture, a new architecture to improve the security of e-city's systems and their provided services and also overcoming the challenges of information systems has been proposed.
\end{abstract}

\section{KEYWORDS}

E-city, service-oriented architecture, information systems, integration, security as a service, Participation strategies

\section{INTRODUCTION}

In today's world, the rapid growth of cities and it's outpacing from managerial abilities and sources have hugely challenged them in providing adequate city services. According to the development of information and communication technology (ICT), governments are obliged to use of these technologies properly to remain in global competitiveness board and reduce costs and unemployment in their communities [1,2].

There is no comprehensive and complete definition for e-city. Dr. Jalali One of the renowned experts in the field of IT. His definition of an e-city: "a city which can provide different city services, including government services, municipality services and the private sector in the areas of economic, social and cultural in 24 hours of a day and 7 days a week with appropriate quality by using information and communication technology"[1]. In other words, e-city is a project that focuses on improvement and updating of the engineering networks to create an information public space at a particular area [2, 3, and 4]. For maximum use and development of e-city, offer a 
framework for the architecture of e-city is one of the most fundamental and most basic tasks [3] and includes of important sectors such as transforming from present state to an appropriate state that are general polices and lines of e-city development [5].

The most important stages in e-city development are safety and integration that makes the setting up effective communication with users to respond to questions and their needs possible. Different methods have been suggested to integrate of information systems in e-city [2, 3]. SOA is the most important approach used in this field and is a standard framework which in it, the services are creation, development and managed. Also, service-oriented architecture aim is the create an integrated and safety interface for city users and increase of agility of IT in order to rapid reaction to business changes [2, 6, 7]. Using this architecture, we can reduce the development costs of new elements and expansion of existing components. So, will increase speed, security and reliability of services and will recover integrated management of city network [4].

Continue on with this paper studying information systems, e-city architecture and challenges of information systems in e-city layers and with focuses on the benefits of SOA, a new architecture for improvement the security of e-city's systems, their provided services and increase the participation and also overcoming the challenges related to information systems has been proposed.

\section{INFORMATION SYSTEMS}

The IT architecture is an integrated framework for the pro-motion or maintenance of existing technology and acquiring new information technology to achieve the organization's strategic goals and management of its resources [2,8]. The IT architecture which is also known as enterprise architecture is looking to provide an organizational framework for the coordination and alignment of all activities and elements of information technology within an organization. NIST Institute for IT architecture has introduced a 5-layer model which includes: Business architecture layer, information architecture layer, application or information systems architecture layer, data architecture layer and Technology architectures layer [2,9]

- Business architecture layer: The order of this layer in an organization is missions, goals, perspective and its long-term strategies which in fact express existential cause of organization and the way that achieves its goals.

- Information architecture layer: Organization needs information and information functions to achieve their goals. In this layer, elements and information resources of an organization is being discussed. In other words, in this layer map of organization's proper information flow, is determined to achieve goals and strategies formulated in the previous layer.

- Application or information systems architecture layer: This layer will determine the number and types of proper applications which makes possible producing and accessing to information, to achieve the previous layer's information architecture.

- Data architecture layer: In this layer content and form of organization database, patterns of storage and their ex-change will be discussed.

- Technology architectures layer: In lowest layer necessary hardware, software and communication environment for the information systems implementation and information flow will be determined. Elements of this layer are exposed to the most rapid changes and transformation.

According to the model proposed by NIST, information systems fit in application architecture layer [2]. These systems are responsible for tasks such as information gathering, pro-cessing, 
storage, analysis and distribution of information. Such systems make the effective use of IT in an organization possible $[10,11]$.

\subsection{Benefits of information systems}

TABLE1. BENEFITS OF INFORMATION SYSTEMS $[2,10,11]$ :

\begin{tabular}{|ll|}
\hline & Greater participation in decision-making \\
\hline & Increase the speed and quality of decision-making \\
\hline & Increasing speed in identifying issues \\
\hline & Establishing effective communication between the organization units as well as other organizations \\
\hline & Increasing the speed, accuracy and functionality \\
\hline & Improving the effectiveness and efficiency \\
\hline & Get used for various applications in the enterprise \\
\hline & Storage capability, recovery, analysis and information re-sources share \\
\hline
\end{tabular}

\section{E-CITY}

Electronics City (e-city) is a definition for expressing kind of services that can be offered to citizens of a community with modern e-services [1]. E-city is known as a structure for the provision of e-services to citizens. Which are consists of layers; Stakeholders, service providing channels, e-services and technology platforms [12]. The highest layer consists of industries, citizens and even governmental institutions. The next layer that acts as a channel of communication can also include a variety of browsers and types of telecom equipment. The electronic services layer consists of set of e-services such as electronic learning, electronic shop, electronic banking, electronic insurance. Platforms which provider e-services are located in last layer. These platforms are distributed in different organizations and locations, and each one is designed with specific technology on the other hand they are capable of interaction and incorporation with other platforms $[2,3,12]$.

Another of major issue in implementing e-city is type of services. Type of service must be appropriate to the circumstances of a city, because each city has different characteristics. Its need to establish basic policies on the basis of policies conducted by other organs, to avoid wasting resources and systems should be implemented with high integrity [13]. This issue causes that government to develop their services with detailed plan and according to actual needs of cities. The introduced service will be integrated and the lifetime of the projects will be increased $[2,3]$.

\subsection{Reasons of E-city implementation}

The main reason for the investment and use of various technologies in the delivery of services to citizens is believe that city and managerial problems have inverse relation with citizens' awareness increase [1]. In Table 2 we can point to E-city achievements based on this important topic [1]. 
TABLE2. REASONS OF E-CITY IMPLEMENTATION

\begin{tabular}{|ll|}
\hline & Improve in management sight \\
\hline & Integrated information system \\
\hline$*$ & Optimizing information flow \\
\hline & Suppliers' support and relations \\
\hline & Change in organizational culture \\
\hline & Decrease of fuel consumption \\
\hline & Flexibility of organizational processes \\
\hline & Cncreasing customers bargaining power \\
\hline & Decrease of necessary traffic, number of car accidents and their casualties \\
\hline
\end{tabular}

E-city is comprised of multiple information systems and one of the main challenges is the providing architecture for the interaction between information systems, increase security and integration of these systems to provide appropriate quality services to the users [2]. Therefore, according to service-oriented architecture capabilities as a computational model and an approach for integrating information systems and the interaction between them continue on with overview of service-oriented architecture, we propose a new service-oriented architecture to overcome the challenges of the security of information systems.

\section{SERVICE ORIENTED ARCHITECTURE}

SOA is lightness of design, which focuses on all aspects of implementation and using business services during their life cycle. It also is a way to prepare the required infrastructure for the exchange of information among different applications on any OS and programming language they've been created $[2,14]$. SOA is a standard framework and its goal is increase of IT agility to rapidly respond to business changes and create an integrated interface for city users [6,7]. Using this architecture can decrease the cost of developing new elements as well as the existing elements development and also speed, reliability and security will be increased and will improve the integrated management of city network [4].

The main goal of the provide a SOA is to cope with challenges such as the lack of integration and interaction of information systems in organizations and lack of the IT's ability to adapt the business's changes speed according to the organizations constant need to changing of processes and services, difference among experts of IT and experts of business in views [2, 3].

TABLE3: THE MOST IMPORTANT GOALS OF OFFERING A SOA $[2,3,15]$

\begin{tabular}{|ll|}
\hline & Upgrade IT coordinated with business \\
\hline & Improvement of the interaction between organizations \\
\hline$*$ & Flexibility of IT to respond to on-going changes in business \\
\hline & Standardization and integration of platforms and IT substructures \\
\hline & Flexibility of software components and improvement of the level of reuse \\
\hline
\end{tabular}




\section{THE PROPOSED ARCHITECTURE}

As we noticed, service oriented architecture is a good approach to create interaction and integration in e-city. But some challenges are hindering the implementation of e-city that the most important was stated security issues. Now we will propose an architecture which through implementation of e-city with it, large extent of security issues and challenges associated with it can be solved and with the notion fairly comfortable benefit from the services offered by e-city.

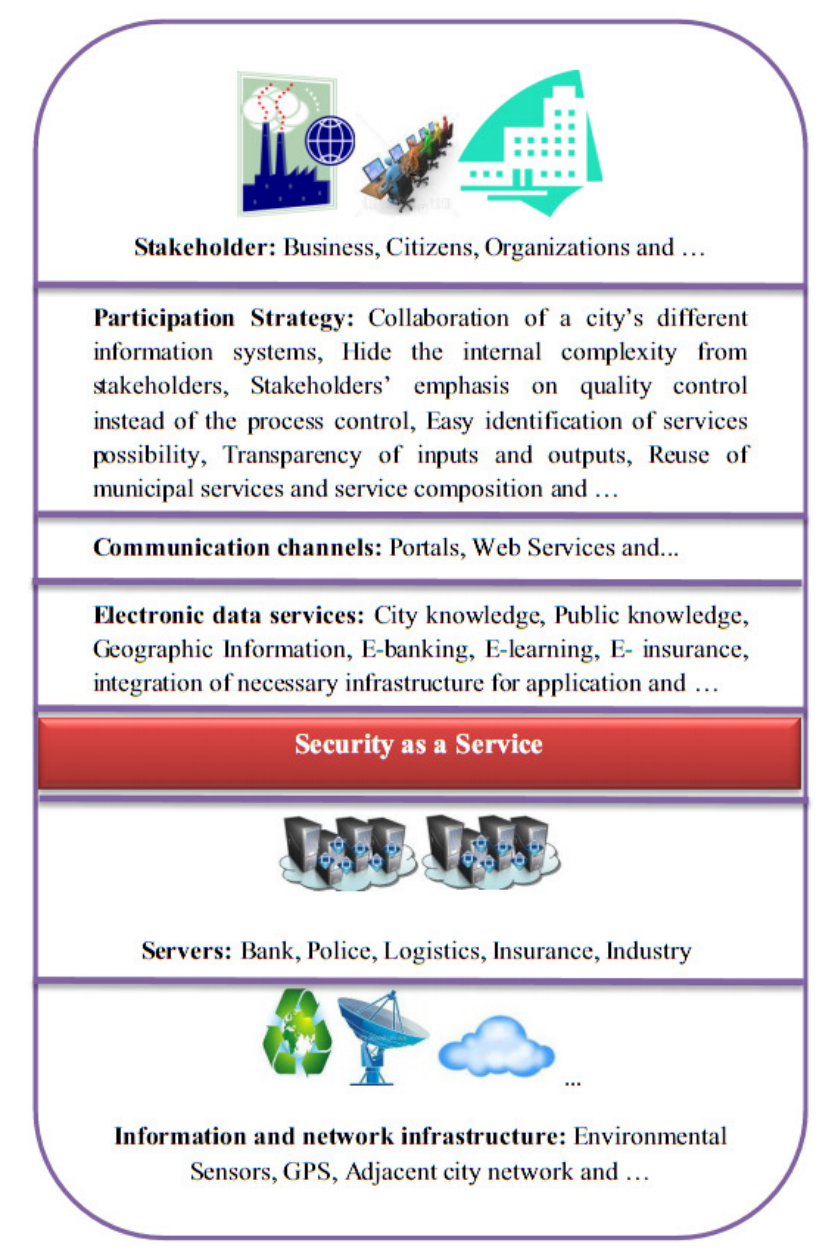

Figure 1. The PRoposed ARCHITECTURE to SECURE SERVICES IN E-City

According to the architecture needs, each of the layers is responsible to the following tasks:

1) Stakeholder layer: provides APP services for users, organizations, citizens, etc.

2) Participation strategies Layer: This layer has been placed for strategies to get maximum attraction of citizens and explaining policies to participate in E-city.

3) Communication channels layer: this layer is placed to create a connecting bridge for accessing provided services by e-city, that can includes variety browsers and or telecommunication equipment connectable to the internet. 
4) Electronic data services layer: this layer provides a broad collection of e-services such as e-banking, e-learning, e-insurance, integration of necessary infrastructure for application and data transfer to ultimate goal in network.

5) Security as a Service layer: this layer is to establish a secure and provide secure and reliable services to the users, in fact security as a service means that service applicant depending on the type of service and Concurrent with the re-quested service will request required Level security as a separate service. In simple words, based on real-world systems where necessary security is provided in accordance with the individual or organization position, here also depending on how important the requested service is, naturally it will need higher security to protect data. For example, a service requested by the user for banking needs stronger security compared to a service requested to perform simple administrative matters.

6) Systems and Servers layer: this layer is used to organize and process information, management of information flow and Services of data systems, City data and allocate them to knowledge base.

7) Information and network infrastructure layer: this layer is used to provide information and city systems. In fact, raw data will be given to upper layer by this layer to process and allocate them to knowledge base

\section{Conclusions}

Most of the activities are conducted over the Internet and electronic systems in e-cities and its purpose is citizens' access to all required information in entire week and at all hours and in a stable, reliable and confidential manner. The main challenge in architecture presentation for ecities is to create interaction between information systems and create a trusted and secure environment. On this basis, and to overcome outlined challenges, we presented a 7 layered architecture, including stakeholders layer, participation strategies layer, channels of communication layer, electronic data services layer, security as a service layer, systems and servers layer and information and network infrastructure layer. The proposed architecture can partially overcome the problems mentioned and provides a secure and interoperable environment for e-city information systems. Also, the success of any system depends the number of users and the efficiency of the system. To increase participation in a system, elements of satisfying of users should be provided. Therefore, in the architecture that we proposed in a discrete layer we put elements such as the independency of the services during calls by various stakeholders, reuse of municipal services and service composition, transparency of inputs and outputs, easy identification of services possibility, stakeholders' emphasis on quality control instead of the process control, hide the internal complexity from stakeholders, collaboration of a city's different information systems to increase the participation and satisfaction of users of the system.

\section{REFERENCES}

[1] H. Tohidi, M.M. Jabbari, "The main requirements to implement an electronic city", Procedia Computer Science, Volume 3, pp.1106-1110, 2011.

[2] S. Hashemi, I.Maleki, S.R.Khaze, Gharehchopogh, “ A new Service Oriented based Architecture for Increasing Security in Electronics City”, Fourth Conference Electeronic Government Softwares, Geshm Smart Island, Iran 2013.

[3] S. Hashemi, S. Y. Hashemi," A Novel Service Oriented Architecture for Integration of Information Systems in Electronic City", international journal of scientific \& technology research volume 1, issue 11, pp.6-9, 2012.

[4] Evgen Duravkin,E., "Using SOA for development of information system (Smart city)", Modern Problems of Radio Engineering, Telecommunications and Computer Science (TCSET), pp. 258 258, 12 April 2010. 
[5] M.R. Zynoddini, An Enterprise Architecture Framework for Electronic City, Master Thesis, Payame Noor University, Iran, 2011.

[6] Thomas Erl, "Service-Oriented Architecture (SOA): Concepts, Technology, And Design", Prentice Hall Ptr, 760 p., 2005.

[7] Arsanjani, A., "Service Oriented Modeling and Architecture", In: IBM Business Consulting Services, pp. 1-4, 2004.

[8] AL-HADER M., RODZI A.” The smart city infrastructure development \& monitoring”, Theoretical and Empirical Researches in Urban Management NO 2(11), pp. 87-94, 2009.

[9] Elizabeth N. Fong and Alan H. Goldfine , Information Management Directions: The Integration Challenge., National Institute of Standards and Technology (NIST) Special Publication 500-167, September 1989.

[10] Lewis Carr, Geoff Linton, "Oracle's Solutions for Smart Cities”, Delivering 21st Century Services, DATE U P Volume 1. No. 11. April to June 2010

[11] Freeman, P. and Aspary, W., "The Supply of Information Technology Workers in the United States, Washington D.C. “,Published by Jossey-Bass, A Wiley Company, pp. 5-20,1999.

[12] A. Mahjorian, F. Shams. "Designing a Service-oriented Enterprise based on SOA Principles.”, The 6th Intl. Conf. on Information and Communication Technology Management, Tehran, Iran, pp. 1-6, February 2010.

[13] Berntzen, L., Olsen, M.G, "Benchmarking e-Government - A Comparative Review of Three International Benchmarking Studies", This paper appears in: Digital Society, ICDS '09. Third International Conference on, pp. 77 - 82, 13 February 2009.

[14] Newcomer, E., Lomow, G., "Understanding SOA with Web Service”, Pearson Education, 2005.

[15] Patriatech group, "Need to Service Oriented Architecture", 2012, http://www.partiatech.com/solution/soa/index.php [accessed: 2 Oct 2013].

\section{Authors}

Sajjad Hashemi is a M.Sc. student in Computer Engineering Department, Science and Research Branch, Islamic Azad University, West Azerbaijan, Iran. His interested research areas are in the cloud computing, e-government.

Seyyed Yasser Hashemi is Faculty member of the Department of Computer Engineering, miyandoab Branch, Islamic Azad University, miyandoab, Iran. His interested research areas are in the image processing, cloud computing, e-government.

Dr. Khalil Monfaredi received the B.Sc., M.Sc., and PhD degrees from Tabriz University in 2001 and Iran University of Science and Technology in 2003 and 2011, respectively. He was with Electronic Research Center Group, during 2001 to 2011 and was also an academic staff with Islamic Azad University, Miyandoab Branch from 2006 to 2012. He served as the Research and Educational Assistant of Miyandoab Sama College from 2009 to 2011 and
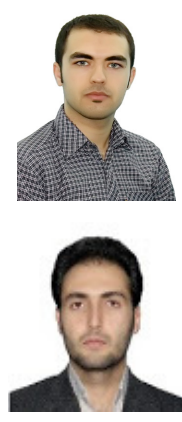
vice chancellor during 2011 to 2012. He is currently with Electrical and Electronics Engineering Faculty, Azarbaijan Shahid Madani University, Tabriz 5375171379, Islamic Republic of Iran. $\mathrm{He}$ is the author or coauthor of more than thirty national and international papers and also collaborated in several research projects. He is also the founder of electronic department in Islamic Azad UniversityMiyandoab Branch and was the chairman of 2010 electronic and computer scientific conference (ECSC2010) held in Islamic Azad University, Miyandoab Branch. His current research interests include current mode integrated circuit design, low voltage, low power circuit and systems and analog microelectronics, data converters, image processing, cloud computing, e-government. 